\title{
Phenotypes contribute to treatments
}

\author{
Yingmeng Ni and Guochao Shi
}

Affiliation: Department of Pulmonary Medicine, Ruijin Hospital, Shanghai Jiao Tong University School of Medicine, Shanghai, People's Republic of China.

Correspondence: Guochao Shi, Department of Pulmonary Medicine, Ruijin Hospital, Shanghai Jiao Tong University School of Medicine, 197, Rui Jin Er Road, Shanghai 200025, P. R. China. E-mail: shiguochaola hotmail.com

@ERSpublications

More exact COPD phenotyping will provide more precise and personalised treatment for patients http://ow.ly/y3h6309fY9Y

Cite this article as: Ni Y, Shi G. Phenotypes contribute to treatments. Eur Respir J 2017; 49: 1700054 [https://doi.org/10.1183/13993003.00054-2017].

Chronic obstructive pulmonary disease (COPD) is now considered a markedly complex and heterogeneous disease [1]. In the latest update of the Global Initiative for Chronic Obstructive Lung Disease (GOLD 2017) [2], the definition of COPD has been revised to emphasise the heterogeneity of this disease. The phrase "airway and/or alveolar abnormalities" replaces "an enhanced chronic inflammation" in the definition of GOLD 2016. The two most common forms of pathology, namely small airway disease (chronic bronchitis) and parenchymal destruction, both cause chronic airflow limitation, but to different degrees over time [2]. Thus, distinct phenotypes exist and represent single or combined disease components that define the differences between individuals with COPD, as they relate to clinically meaningful outcomes, such as symptoms, exacerbation, rate of disease progression or death, and response to treatment [3].

In this issue of the European Respiratory Journal, KoвLIzeK et al. [4] report an international, multicentre, observational cross-sectional study of COPD subjects in ten Central and Eastern European Countries, the POPE study. 3362 Patients with COPD were recruited and stratified according to the phenotypes recommended by the Spanish and Czech COPD guidelines [5-7]: 63\% were considered non-exacerbators (NON-AE); 20.4\%, with asthma-COPD overlap syndrome (ACOS); 9.5\%, frequent exacerbators with chronic bronchitis (AE-CB); and 6.9\%, frequent exacerbators without chronic bronchitis (AE NON-CB). Multidimensional tools have been used to categorise COPD phenotypes, including clinical symptoms, lung function, imaging, genetic analysis, etc. However, only a few phenotypes have been validated, including $\alpha 1$-antitrypsin deficiency, frequent exacerbations (two or more per year), chronic bronchitis and upper lobe emphysema with poor exercise tolerance [8]. At present, the manner in which phenotypes are categorised differs among various countries, probably because of differences in the various national healthcare systems, and different opinions regarding the cost-effectiveness of drugs, reimbursement issues and availability of medications. A review of national guidelines for COPD in Europe [9] showed variability across national guidelines with respect to the identification of patient subtypes. The German guidelines published in 2007 do not take phenotypes into consideration, whereas more recent guidelines generally recognise multiple patient phenotypes. The classic phenotypes of chronic bronchitis and emphysema have been recognised in the Czech Republic, England and Wales, Poland, Russia and Spain, with relatively consistent criteria. The asthma-COPD overlap syndrome (ACOS) phenotype has been recognised in recommendations from the Czech Republic, Finland, Russia, Spain and Sweden. Although variability in the cut-off value exists, the main diagnostic criteria of ACOS are similar, including reversibility in bronchodilator testing, exhaled nitric

Received: Jan 102017 | Accepted: Jan 112017

Support statement: Support was received from the National Natural Science Foundation of China (ref. 81470216). Funding information for this article has been deposited with the Crossref Funder Registry.

Conflict of interest: None declared.

Copyright CERS 2017 
oxide fraction, elevated sputum eosinophils and history of asthma [7, 10-15]. The fourth most recognised phenotype is the frequent exacerbator phenotype; however, its definition differs in the guidelines of different countries. The Czech Republic guidelines [10] define frequent exacerbators as those with a history of two or more exacerbations over the past year. The guidelines from Finland, Russia, Portugal and Spain define frequent exacerbators as those who have had two or more exacerbations or one or more severe exacerbations leading to hospitalisation in the previous year [7, 9, 11-13, 15]. In Poland, patients with forced expiratory volume in $1 \mathrm{~s}<50 \%$ predicted are also considered frequent exacerbators because of the high risk of exacerbations [16].

GOLD categories A-D were proposed for the first time in 2011 [17]. They are composed of two dimensions, the COPD assessment test (CAT) and the modified Medical Research Council (mMRC) dyspnoea score for presenting symptom evaluation, lung function (GOLD stage classification) and exacerbation frequency for future risk evaluation. A series of validation studies has been conducted in different region, and showed some similar results, such as a relatively low number of category $\mathrm{C}$ patients, significant heterogeneity in prospective exacerbation rates in category $\mathrm{D}$, no differences in the predictive value of mortality for GOLD 2011 and GOLD 2007, and a better predictive value of exacerbation for GOLD 2011 and GOLD 2007 [18]. KoвLIzek et al. [4] also compared Spanish phenotypes with GOLD categories (2011 version) and showed that the majority of frequent exacerbators were in category D regardless of the coexistence of chronic bronchitis, whereas $39 \%$ of non-exacerbators and $56 \%$ of those with ACOS were also in category $\mathrm{D}$, indicating marked heterogeneity in this category. In the 2017 update of GOLD, lung function (GOLD stages 1-4) is considered independent of the assessment of GOLD categories $\mathrm{A}-\mathrm{D}$, the predictive values of which need to be validated [2].

The phenotypes mentioned above mainly consider clinical signs, for example chronic bronchitis, dyspnoea, exacerbations and lung function. However, these signs cannot reflect all of the underlying pathobiology, including airway remodelling, lung damage and inflammation [19]. The presence of airway inflammation in both stable COPD and exacerbation episodes is well recognised. Sputum cytology has facilitated the identification of different sputum phenotypes, as determined by granulocyte composition, referred to as neutrophilic, eosinophilic, mixed granulocytic and pauci-granulocytic [20, 21]. Sputum eosinophilia is present in $10-40 \%$ of all patients with COPD [22-25]. Patients with persistent eosinophilia show faster emphysema progression, without rapid lung function decline, as compared to patients with intermittent eosinophilia [26]. Different exacerbation phenotypes have also been explored. BAFADHIEL et al. [27] observed 145 patients over one year. Serum cytokines and chemokines were assessed at a stable state and during exacerbations to identify biomarkers. Four biological exacerbation clusters were identified using unbiased cluster analysis: proinflammatory bacterial-predominant (high level of IL-1 $\beta$ and TNF $\alpha$ ); T-helper lymphocyte type 1 viral-predominant (high level of CXCL10 and CXCL11); T-helper lymphocyte type 2 eosinophilic-predominant (high level of IL-5, CCL13 and CCL17); and pauci-inflammatory with limited change in the inflammatory profile.

The ultimate goal of phenotype is the better clinical management, and phenotype-specific clinical management is eagerly desired. Inhaled corticosteroids are questionable owing to the unclear long-term safety [28]. Considering that the presence of sputum eosinophilia $(>3 \%)$ in COPD is a good predictor of the response to inhaled corticosteroid treatments in stable disease, inhaled corticosteroids should be selectively used for this subset of patients, rather than for all COPD patients. In acute exacerbations of COPD, targeting oral corticosteroid treatment to those patients with evidence of eosinophilic airway inflammation can lead to a safe reduction in the prescription of oral corticosteroids [29]. Another anti-inflammatory agent, Roflumilast can reduce moderate and severe exacerbations in patients with chronic bronchitis and a history of exacerbations [30]. Some new agents have proven effective in a subset of COPD patients. Benralizumab (monoclonal antibody of IL-5R $\alpha$ ) improved lung function in COPD patients with sputum eosinophilia, but did not decrease exacerbation rates, although there was a trend toward reduction in exacerbations and improvement in health status [31].

COPD phenotype is important to provide patients with precise and personalised medicine. Most phenotypes used to date rely essentially on clinical and physiological variables, and biological markers may complete them. Given the complex of possible parameter combination, clinicians should select the tools to be used according to the aim, such as prognosis evaluation, treatment response evaluation, or research [32].

\section{References}

1 Agusti A, Gea J, Faner R. Biomarkers, the control panel and personalized COPD medicine. Respirology 2016; 21: 24-33.

2 Global Initiative for Chronic Obstructive Lung Disease. Global strategy for the diagnosis, management and prevention of chronic obstructive lung disease. http://goldcopd.org/gold-2017-global-strategy-diagnosis-management-preventioncopd/ Date last accessed: December 28, 2016. Date last updated: 2016. 
3 Han MK, Agusti A, Calverley PM, et al. Chronic obstructive pulmonary disease phenotypes: the future of COPD Am J Respir Crit Care Med 2010; 182: 598-604.

4 Koblizek V, Milenkovic B, Barczyk A, et al. Phenotypes of COPD patients with a smoking history in Central and Eastern Europe: the POPE Study. Eur Respir J 2017; 49: 1601446.

5 Zbozinkova Z, Barczyk A, Tkacova R, et al. POPE study: rationale and methodology of a study to phenotype patients with COPD in Central and Eastern Europe. Int J Chron Obstruct Pulmon Dis 2016; 11: 611-622.

6 Miller MR, Hankinson J, Brusasco V, et al. Standardisation of spirometry. Eur Respir J 2005; 26: 319-338.

7 Miravitlles M, Soler-Cataluña JJ, Calle M, et al. Spanish guideline for COPD (GesEPOC). Update 2014. Arch Bronconeumol 2014; 50: Suppl. 1, 1-16.

8 Celli BR, Decramer M, Wedzicha JA, et al. An official American Thoracic Society/European Respiratory Society statement: research questions in COPD. Eur Respir J 2015; 45: 879-905.

9 Miravitlles M, Vogelmeier C, Roche N, et al. A review of national guidelines for management of COPD in Europe. Eur Respir J 2016; 47: 625-637.

10 Koblizek V, Chlumsky J, Zindr V, et al. Chronic obstructive pulmonary disease: official diagnosis and treatment guidelines of the Czech Pneumological and Phthisiological Society; a novel phenotypic approach to COPD with patient-oriented care. Biomed Pap Med Fac Univ Palacky Olomouc Czech Repub 2013; 157: 189-201.

11 Kankaanranta H, Harju T, Kilpeläinen $M$, et al. Diagnosis and pharmacotherapy of stable chronic obstructive pulmonary disease: the Finnish guidelines. Basic Clin Pharmacol Toxicol 2015; 116: 291-307.

12 Chuchalin AG, Avdeev SN, Belevskiy AS, et al. Russian Respiratory Society Federal Guidelines on Diagnosis and Treatment of Chronic Obstructive Pulmonary Disease. http://pulmonology.ru/pulm/article/view/234/233 Date last accessed: December 28, 2016. Date last updated: 2014.

13 Miravitlles M, Soler-Cataluña JJ, Calle M, et al. Spanish COPD guidelines (GesEPOC): pharmacological treatment of stable COPD. Spanish Society of Pulmonology and Thoracic Surgery. Arch Bronconeumol 2012; 48: 247-257.

14 Holm LE. National guidelines for care in asthma and COPD-support for governance and managementconsultation version. www.socialstyrelsen.se/sitecollectiondocuments/nr-astma-kol-vetenskapligt-underlag-2015.pdf Date last accessed: December 28, 2016. Date last updated: 2014.

15 Health Ministry, Portugal. Diagnóstico e Tratamento da DoençaPulmonarObstrutivaCrónica. [Diagnosis and treatment of chronic obstructive pulmonary disease.] Standard No. 028/2011. www.dgs.pt/directrizes-da-dgs/ normas-e-circulares-normativas/norma-n-0282011-de-30092011-atualizada-a-10092013.aspx Date last accessed: December 28, 2016. Date last updated: September 10, 2013.

16 Sliwiński P, Górecka D, Jassem E, et al. Polish respiratory society guidelines for chronic obstructive pulmonary disease. Pneumonol Alergol Pol 2014; 82: 227-263.

17 Global Initiative for Chronic Obstructive Lung Disease. Global strategy for the diagnosis, management and prevention of chronic obstructive lung disease. www.goldcopd.org/uploads/users/files/GOLD_Report_2011_Feb21. pdf Date last accessed: December 28, 2016. Date last updated: February 11, 2011.

18 Chen CZ, Ou CY, Hsu CH, et al. Validation of the GOLD 2013 classification in predicting exacerbations and mortality in Taiwanese patients with chronic obstructive pulmonary disease. J Formos Med Assoc 2015; 114: 1258-1266.

19 Brightling CE. Chronic obstructive pulmonary disease phenotypes, biomarkers, and prognostic indicators. Allergy Asthma Proc 2016; 37: 432-438.

20 Simpson JL, Scott R, Boyle MJ, et al. Inflammatory subtypes in asthma: assessment and identification using induced sputum. Respirology 2006; 11: 54-61.

21 Brightling CE. Clinical applications of induced sputum. Chest 2006; 129: 1344-1348.

22 Brightling CE, Monteiro W, Ward R, et al. Sputum eosinophilia and short-term response to prednisolone in chronic obstructive pulmonary disease: a randomised controlled trial. Lancet 2000; 356: 1480-1485.

23 Brightling CE, McKenna S, Hargadon B, et al. Sputum eosinophilia and the short term response to inhaled mometasone in chronic obstructive pulmonary disease. Thorax 2005; 60: 193-198.

24 Pizzichini E, Pizzichini MM, Gibson P, et al. Sputum eosinophilia predicts benefit from prednisone in smokers with chronic obstructive bronchitis. Am J Respir Crit Care Med 1998; 158: 1511-1517.

25 Siva R, Green RH, Brightling CE, et al. Eosinophilic airway inflammation and exacerbations of COPD: a randomised controlled trial. Eur Respir J 2007; 29: 906-913.

26 Singh D, Kolsum U, Brightling CE, et al. Eosinophilic inflammation in COPD: prevalence and clinical characteristics. Eur Respir J 2014; 44: 1697-1700.

27 Bafadhel M, McKenna S, Terry S, et al. Acute exacerbations of chronic obstructive pulmonary disease: identification of biologic clusters and their biomarkers. Am J Respir Crit Care Med 2011; 184: 662-671.

28 Boardman C, Chachi L, Gavrila A, et al. Mechanisms of glucocorticoid action and insensitivity in airways disease. Pulm Pharmacol Ther 2014; 29: 129-143.

29 Bafadhel M, Greening NJ, Harvey-Dunstan TC, et al. Blood eosinophils and outcomes in severe hospitalised exacerbations of COPD. Chest 2016; 150: 320-328.

30 Calverley PM, Rabe KF, Goehring UM, et al. Roflumilast in symptomatic chronic obstructive pulmonary disease: two randomised clinical trials. Lancet 2009; 374: 685-694.

31 Brightling CE, Bleecker ER, Panettieri RA Jr, et al. Benralizumab for chronic obstructive pulmonary disease and sputum eosinophilia: a randomised, double-blind, placebo-controlled, phase 2a study. Lancet Respir Med 2014; 2: 891-901.

32 Roche N. Adding biological markers to COPD categorisation schemes: a way towards more personalised care? Eur Respir J 2016; 47: 1601-1605. 